\title{
Ultrastructural Studies of The Pigment Epithelium of Retinae of Some Reptiles
}

\author{
Fairoze Khattab ; Fahmy I. Khattab; Nagui Fares and Aman Zaki \\ (Department of Zoology, Faculty of Science ,Ain Shams University, \\ Abbassia, Cairo, Egypt.
}

\begin{abstract}
The present work was designed to reveal the fine structure of the pigment epithelium of the retina in four different reptiles: the homed viper Cerastes cerastes (diurnal and nocturnal), the European Chameleo chameleon (diurnal),the gold skink Eumeces schenrdii (diurnal) and the Egyptian gecko Traentola annularis (nocturnal). The pigment epithelium of each type reptiles possessed certain unique features in their morphology and ultrastructure to accommodate with their day and night activity. The most striking feature was the presence of myoid bodies in the pigment epithelium of the diurnal reptiles. These bodies trigger the photomechanical movement of the myoid region in cones of their retinae.
\end{abstract}

\section{Introduction}

The visual system of vertebrates and many higher invertebrates has evolved to provide a detailed picture of the surrounding environment (Bowmaker, 1991). Retina is the light sensitive part of the eyes . It is located near the eye, corresponding to the film of the camera (Villee et al. ,1989).The retinal pigment epithelium (RPE) is the outer most (scleral) layer of the retina. It has several processes which accommodate with the proper function of the photoreceptors and ultimately to vision itself (Braekevelt and Richardson 1996). The melanin granules of the pigment epithelium act as photo pigment involved in protecting the retina from sudden bright junctions, directly with the iris muscles (Moyer,1969). As a consequence of these several important functions, these region of the vertebrate retina has been investigated in a variety of animals and with variety of techniques. Morphological studies have shown as remarkable similarity throughout vertebrate species but with phylogenetic differences usually present (NguyenLegros, 1978;Kuwabara, 1979 ,Braekevelt, 1980, 1986, 1988,1992,1993 and 1994).

\section{Materials And Methods}

In the present work, four adult Egyptian reptiles, the homed viper (Cerastes cerastes), European Chameleon (Chameleo chameleon), gold skink
(Eumeces schenrdii)and Egyptian gecko (Tarentola annularis) were used. All animals under investigation were collected from Abou-Rawash district ,Giza Governarate, in Egypt.

Animals were sacrificed and the whole eye of each animal was quickly removed. The whole eye was then placed in $5 \%$ glutraldehyde, buffered to $\mathrm{pH} 7.3$ at $4{ }^{\circ} \mathrm{C}$ .after one hour a circular cut was made parallel to the corneal margin with a sharp razor blade. This caused the division of the eye into two portions. The posterior portion, containing the retina, was cut into small pieces, about $1 \mathrm{~mm}^{2}$ each .The samples were placed in fresh $5 \%$ cold glutraldehyde and fixation was continued for five hours. Samples were then washed in two changes of cold phosphate buffer, $\mathrm{pH} 7.3$,for 1 hour. The specimens were then post-fixed for 1-2 hours in buffered $1 \%$ osmium tetraoxide. They were washed twice for 15 minutes, in phosphate buffer, $\mathrm{pH} 7.3$,then dehydrated in ascending grades of ethanol to propylene oxide and embedded in Araldite each.

Semithin sections of $0.7 \mathrm{~m}$ thickness were cut with glass knives on the 6000 MT RMC ultratome. Stained with $0.25 \%$ toludine blue (Davis,1971).and examined by light microscopy. Thin sections (600$700^{\circ} \mathrm{A}$ ) were then cut and collected on copper grids. These sections were stained 
with uranyl acetate and lead citrate and examined photographed in a JEOL 1200 EXIL transmission electron microscope.

\section{Results}

Light microscopic examination of semithin sections of the retinae of all the four studied reptiles revealed, the presence of ten-well defined layers. These layers are arranged as:pigment epithelium, photoreceptor layer, outer limiting membrane, outer nuclear layer, outer plexiform layer, inner nuclear layer, inner plexiform layer, ganglionic-cell layer, optic nerve fiber layer and inner limiting membrane(Figs.1a,b,c and d).

\section{I.Cerastes cerastes}

The retinal pigment epithelium formed of a single layer of cuboidal cells which have several processes that extend in between the photoreceptors. These processes contain a large number of pigments or melanosomes (Fig.1a)

At the electron microscopy level ,the retinal pigment epithelium consists of a single layer of cuboidal cells which are laterally adhered by a series of tight junctions.

These junctions are located near the base and mid region of the epithelial cells (Fig.2).Numerous processes extend from these cells to separate and lie in between the photoreceptor outer segments (Figs. $2 \& 3)$.

Each of the retinal pigment epithelial cells has a large vesicular nucleus occupying a central position, and has a single nucleolus(Figs.2 \&3).Mitochondria are round to oval in shape (Figs.3\&4). The smooth endoplasmic reticulum is the most abundant cell organelle and is distributed throughout the pigment epithelial cells (Figs.2,3\&4).

Lipid droplets are common features of the retinal pigment epithelial cells of Cerastes cerastes .Large lipid droplets were seen occupying the basal region of these cells (Figs.2\&5). Melanosomes are present through out the retinal epithelial cells, and are predominantly located in the apical region of these cells .These melanosomes are small and round to spindle shaped and possess a high electron dense appearance (Figs.2\&3).The Golgi complexes are often scattered within the cells (Fig. 4).

\section{II.Chameleo chameleon}

The retinal pigment epithelium in the Chameleo chameleon retina is a single layer of cuboidal cells with basal membranous enfolding ,Several processes from their free surface extend in between the photoreceptors with their characteristic large number of melanosomes (Fig. 1.b).Outer segments (Figs.7\&9).Laterally the cell borders of the retinal pigment epithelium RPE cells are relatively smooth and are joined together by a series of basally located tight junctions.(Figs.8\&9).

Internally the retinal epithelial cells displays a single elongated vesicular nucleus located in the mid region of the cell(Figs.7\&8).The smooth endoplasmic reticulum with the exception of the basal enfolding is distributed throughout the cytoplasm of these cells (Figs.6\&9).

Mitochondria are numerous within the retinal epithelial cells and are mainly located in the basal region of the cell adjacent to the basal enfolding. These mitochondria are quite variable in shape (Fig.6\&9).

Myoid bodies, which are formed of the stacked array of smooth membranes and are present in the retinal epithelial cells in large numbers and of various shapes(Fig.9) The melanosomes within the retina of pigment epithelium cells are almost exclusively located within the apical processes of these cells. They are small and round to oval in shape (Figs.7, $8 \& 9$ ).

Bruch's membrane separates the retina from the adjacent choriocapillaries of the choroids(Fig.6). This membranous structure is a pentalaminate structure consisting of 1)The basal lamina of the RPE cells,2)The basal lamina of the choriocapillaries, 3)a discontinuous elastic layer (lamina densa), 4)An outer and 5)an inner collaginous layer (Figs.6\&8).

\section{III . Eumeces schendrii}

The pigment epithelial layer appears as a single layer of cells. The epithelial layer is based on a prominent basal lamina underlined by the Bruch's membrane .The later membrane consists of a thick conti- 
nuous layer of elastic tissue (Figs.1c,10 \&11).Electron micrographs revealed that the pigment epithelium consists of a single layer of cuboidal cells joined laterally by a series of tight junctions (figs. $10 \&$ 11). The lateral cell junctions are located near the base and the mid-region of the epithelial cell(Fig.10). The base of the cells have deeply infolded membranes (fig.11). Apically, numerous cytoplasmic processes extend from the epithelial cell body to enclose and separate the photoreceptor outer segments (Fig.11). Internally, the retinal pigment epithelial cells display large and vesicular nuclei. These nuclei occupy a central or a basal position. (Fig.10). Mitochondria are small and numerous and vary in shape from rounded to elongated and are mostly basally located(Fig.11).

The smooth endoplasmic reticulum is the most abundant cell constituent, which is distributed throughout the epithelial cells, except in the basal enfolding(Fig.11).

Lipid droplets and lysosome-like bodies are also a common feature of the retinal pigment epithelium cells (Fig.10). Myoid bodies are frequently located within the cytoplasm of the retinal pigment epithelium. These structures appear as a compact stakes of membranes (Fig.10). Although melanosomes are randomly distributed throughout the cytoplasm, yet they are predominantly located in the apical region of the epithelial cells, These melanosomes are small, rounded or spindle shaped and extremely electron dense(Figs.10\& 11).

\section{IV.Tarentola annularis}

The retinal pigment epithelium layer in Tarentola annularis is a single layer of polyhydral cells which has basal membranous enfolding .Several processes from their inner free surface extend in between photoreceptor with their characteristic large number of melanosomes. These processes interdigitate in between their photoreceptor outer segment ( Figs. 1d, 12, $13 \& 15$ ).

Laterally, the cell border are relatively smooth and are joined together by a series of basally located tight junction (Fig.12).the retinal epithelial cells displayed a slightly rounded nucleus located in the basal region of each cell(Fig.14).
The smooth endoplasmic reticulum, with the exception of the basal enfolding, is distributed throughout the cytoplasm of these cells(Fig.13).Mitochondria are numerous within the retinal epithelial cells and are mainly located in the basal region of these cells. These mitochondria are quite variable in shape.(Figs.13\&14).

Phagosomes are abundant (Figs.13 \& 14).lipid droplets and lysosomes-like bodies were also common in these cells (Fig.12). Melanosomes were present throughout the retinal epithelial cells ,predominantly located in their apical regions(Figs.12\&14).

The melanosomes were small, rounded or spindle-shaped and extremely electron dense, the arrangement of these melanosmes appears quite disorganized in the cells (Fig.12), whereas in the apical processes the melanosomes are aligned with the long axis of both the photoreceptor outer segment and the apical processes (Fig.15)

\section{Explanation Of Figures}

Fig.1.a. A semithin section of the retina of Cerastes cerastes (toluidine blue stain) showing the following layers:

1. Retinal pigment epithelium, with several melanosomes $(\mathrm{Me})$.

2. Photoreceptor layer with large single cones (Lsc), small single cones (ssc) and rods (R).

3. Outer limiting membrane (arrow heads).

4. Outer nuclear layer.

5. Outer plexiform layer with photoreceptor fibers $(\mathrm{Pf})$.

6. Inner nuclear layer, consisting of horizontal cells (hc), bipolar cells (bc), Muller cells(Mu) and amacrine cells (ac).

7. Inner plexiform layer.

8. Ganglionic cells layer.

9. Nerve fiber layer.

10. Inner limiting membrane (arrow heads).

a- $\mathrm{Bar}=1.33 \mathrm{um}$

b- Schematic drawing of the retina of Cerastes cerastes.

Fig.1.b: A semithin section of the retina of Chameleo chameleon, showing the following layers: 
1. Retinal pigment epithelium, with several processes extending into the photore-ceptor layer and containing large number of melanosomes (Me).

2. Photoreceptor layer with double cone (DC) and single cone (SC).Each double cone consists of a principle cone (PC) and an accessory cone (AC).

3. Outer limiting membrane (arrow heads).

4. Outer nuclear layer ,containing the nuclei of the photoreceptor cells.

5. Outer plexiform layer with photoreceptor fiber (pf).

6. Inner nuclear layer comprising horizontal cells (hc), bipolar cells (bc), Muller cells $(\mathrm{Mu})$ and amacrine cells $(\mathrm{ac})$.

7. Inner plexiform layer,represented by the processes of amacrine, Muller, ganglion and bipolar axons.

8. Ganglion cells layer, represented by the ganglion cells with their characteristic large nuclei.

9. Nerve fiber layer.

10. Inner limiting membrane.

a- Bar $=1.33$ um

b- Schematic drawing of the retina of Chameleo chameleon.

Fig.1.c A semithin section of the retina of Eumeces schnedrii, showing the following layers:

1. Retinal pigment epithelium with melanosomes $(\mathrm{Me})$.

2. Photoreceptors layer with single cones (SC) and $\operatorname{rod}(\mathrm{R})$.

3. Outer limiting membrane (arrow heads).

4. Outer nuclear layer.

5. Outer plexiform layer.

6. Inner nuclear layer, comprising horizontal cells (hc),bipolar cells (bc), Muller cells $(\mathrm{Mu})$ and amacrine cells (ac).

7. Inner plexiform layer.

8. Ganglion cells layer with ganglion cells $(\mathrm{G})$ and between them astrocyte cell (as).

9. Nerve fiber layer with astrocyte (as).

10. Inner limiting membrane (arrow heads).

a- $\mathrm{Bar}=1.33 \mathrm{um}$
b-Schematic drawing of the retina of Eumeces Schendrii.

Fig.1.d.A semithin section of the retina of Tarentola annularis showing the following layers:

1. Retinal pigment epithelium with several melanosomes containing processes interdigitating with the photoreceptor cells.

2. Photoreceptor layer; with double rod consists of a principle rod (PR) and an accessory rod (AR). All types of photoreceptors have long outer segment (os).

3. Outer limiting membrane (arrow heads).

4. Outer nuclear layer containing nuclei of photoreceptors.

5. Outer plexiform layer with photoreceptor fibers (pf) and bipolar cells (bc) similar to those of the inner nuclear layer,

6. Inner nuclear layer composed of horizontal cells (hc), bipolar cells (bc), Muller cells $(\mathrm{Mu})$ and amacrine cells.

a- $\operatorname{Bar}=1.33$ um

b-Schematic drawing of the retina of Tarentola annularis.

Fig.2 :Electron micrograph of the retinal pigment of an epithelial cell of Cerastes cerastes, with their characteristic rounded nuclei $(\mathrm{N})$ and prominent nucleoli (nu),cell junction between adjacent cells , abundant smooth endoplasmic reticulum (SER), large highly electron dense lipid droplet (L) and cytoplasmic processes studded with large number of variable shaped melanosomes (Me). This layer is boarded, externally, with the Bruch's membrane (B) and interdigitated, internally, with photoreceptor outer segments (os). $\quad$ X 7500

Fig.3: Electron micrograph of the retinal pigment of an epithelial cell of Cerastes cerastes showing basally located euchromatic nucleus $(\mathrm{N})$ with prominent nucleolus (nu), numerous rounded mitochondria(mi), abundance of smooth endoplasmic reticulum (SER).Several cytoplasmic processes are studded with large number of variable shaped melanosomes $(\mathrm{Me})$. 
This layer is externally covered by Bruch's membrane (B). X 15000

Fig.4 Electron micrograph of the retinal pigment epithelial cells of Cerastes cerastes showing a prominent Golgi apparatus (Ga),mitochondria (mi) with prominent cristae,abundant smooth endoplasmic reticulum (SER) and a part of the nucleus $(\mathrm{N}) . \quad \mathrm{X} 36000$

Fig.5:Electron micrograph of the retinal pigment of epithelial cells of Cerastes cerastes showing a large highly electron dense lipid $\operatorname{droplet}(\mathrm{L})$ and a part of the nuclea $(\mathrm{N}) . \quad$ X 36000

Fig.6:Electron micrograph of the retinal pigment of epithelial cells of Chameleo chameleon showing several basallylocated polymorphic mitochondria (mi) at the basal enfolding (BI) of the retinal pigment epithelium which is separated by the Bruch's membrane (B).X 22500

Fig.7:Electron micrograph of the retinal pigment of epithelial cells of Chameleo chameleon in association with deeply embedded outer segments (os) of photoreceptor .The retinal pigment contains a basal nucleus $(\mathrm{N})$ and several number of round to spindle shape melanosomes (Me). $\quad$ X 15000

Fig.8:Low power electron micrograph of the retinal pigment of epithelial cell of Chameleo chameleon revealing epithelial nuclei (N).cell junction (J) between adjacent cells, several melanosomes (Me), mitochondria (mi) and a Bruch membrane(B). X 15000

Fig.9:Electron micrograph of the retinal pigment of epithelial cells of Chameleo chameleon showing a large myoid body (My), abundance of smooth endoplasmic reticulum (SER), cell junction (J) ,nucleus(N), Bruch's membrane(B) and outer segments (os) of photoreceptor surrounded by the apical processes(AP) of pigment epithelium. $\quad$ X 18000

Fig.10:Low power electron micrograph of the retinal pigment epithelial cells of Eumeces schendrii revealing nuclei(N) of epithelial layer,cell junction (J) between adjacent cells, Golgi apparatus $(\mathrm{Ga})$,lipid $\operatorname{droplet}(\mathrm{L})$ in the basal region, and phagosomes (ph).Several melanosomes $(\mathrm{Me}), \quad$ containing processes intermingle with photoreceptors of both single cones (SC) and rods (R).In the apical region the epithelial cells are limited by Bruch's membrane(B) .

X 9000

Fig.11:Electron micrograph of the retinal pigment of epithelial cells of Eumeces schendrii showing aggregation of myoid bodies (My), numerous mitochondria (mi), smooth endoplasmic reticulum (SER), cell junction (J),basal infoldings (BI) and melanosomes (Me) between the outer segment (os) of photoreceptors. X 12000

Fig.12:Electron micrograph of the retinal pigment epithelial cells of Eumeces schendrii showing a basally located nucleus (N), large lipid droplet (L) ,lyosomes(Ly) ,cells junction (J) and cytoplasmic processes studded with large number of variable shaped melanosomes (Me).This layer is limited ,externally by Bruch membrane

(B). $\quad$ X 22500

Fig.13:Electron micrograph of the retinal pigment of epithelial cells of Eumeces schendrii showing a basally located lipid droplet (L), numerous rounded to elongated mitochondria (mi), abundance of smooth endoplasmic reticulum (SER) and a large phagosomes (ph). Notice the external association thin layer with Bruch's membrane(B) and the interdigitation of its processes with the outer segments (os) of the photoreceptors(os). $\quad$ X 18000

Fig.14:Electron micrograph of the retinal pigment epithelial cells of Tarentola annularis showing a basally located polyhedral nucleus(N) with peripheral and dispersed patches of heterochromatin, prominent nucleolus (nu), phagosomes (ph), melanosomes and the outer Bruch's membrane (B). X 18000

Fig.15:Electron micrograph of photoreceptor layer of Tarentola annularis showing the outer segment (os) and the condensed inner segments (Is) of rods. The apical processes (Ap) of retinal pigment epithelial cells, with their characteristic melanosomes are located between the outer segments of photoreceptors. $\quad$ X 4500 

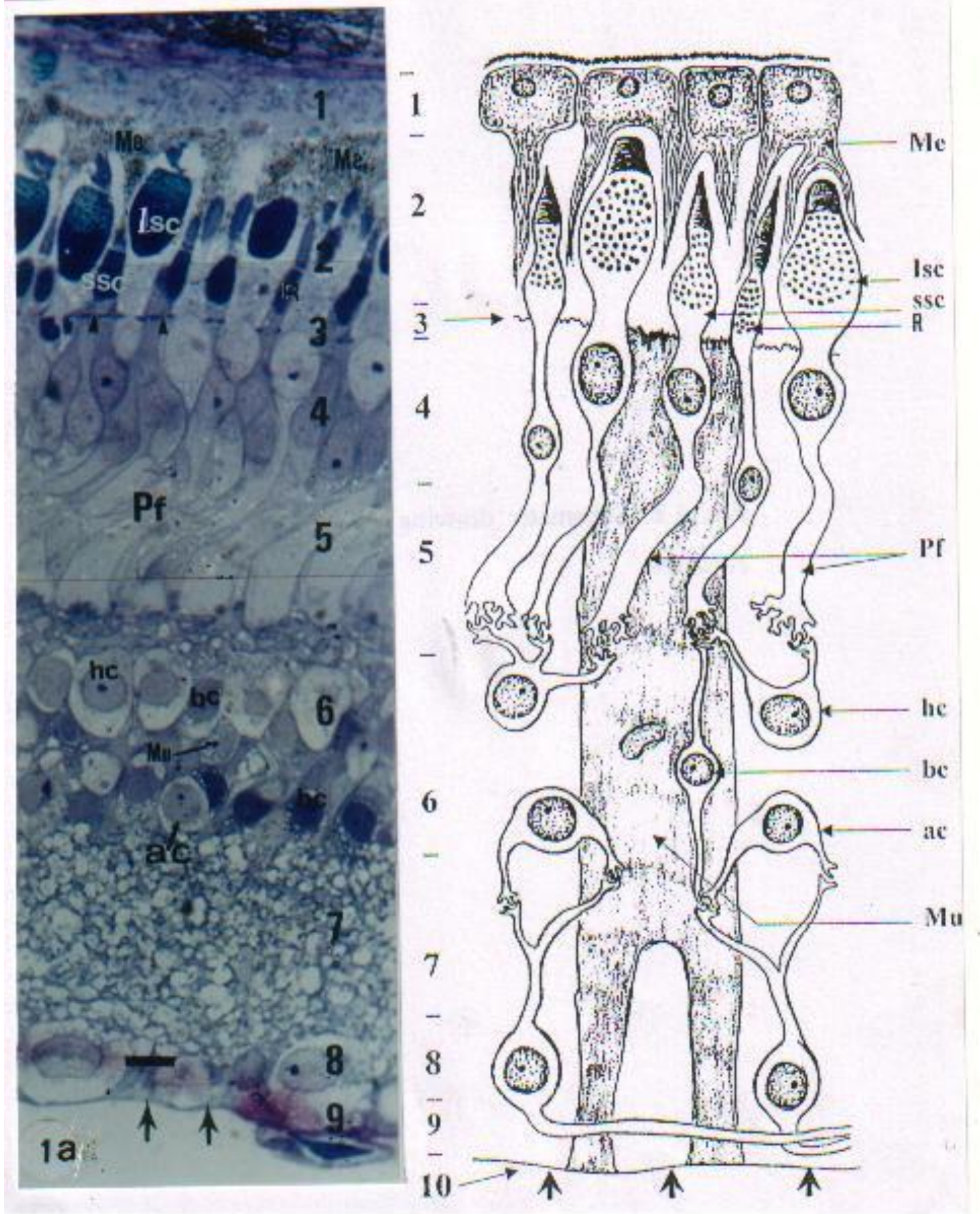
Fairoze Khattab et al

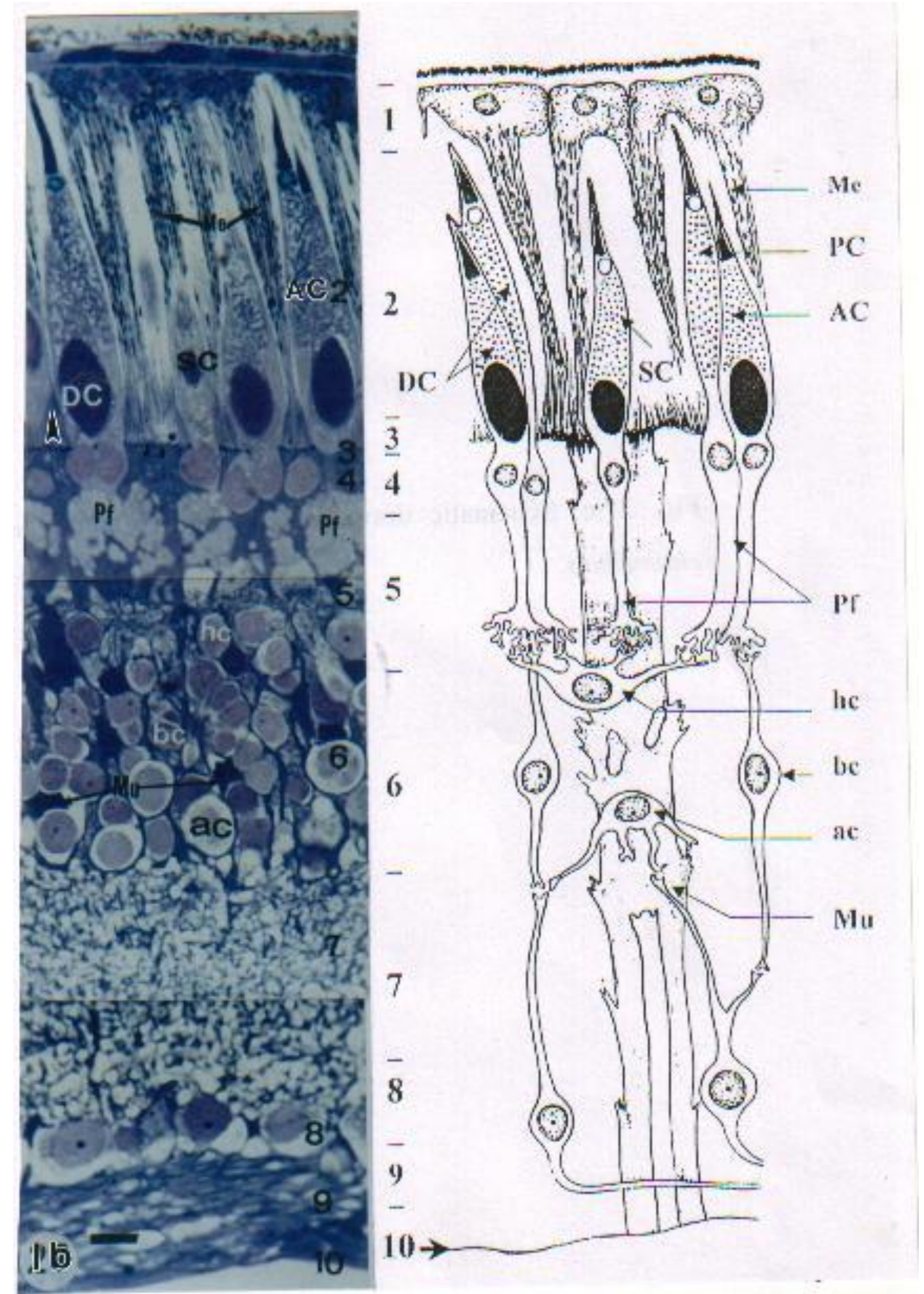




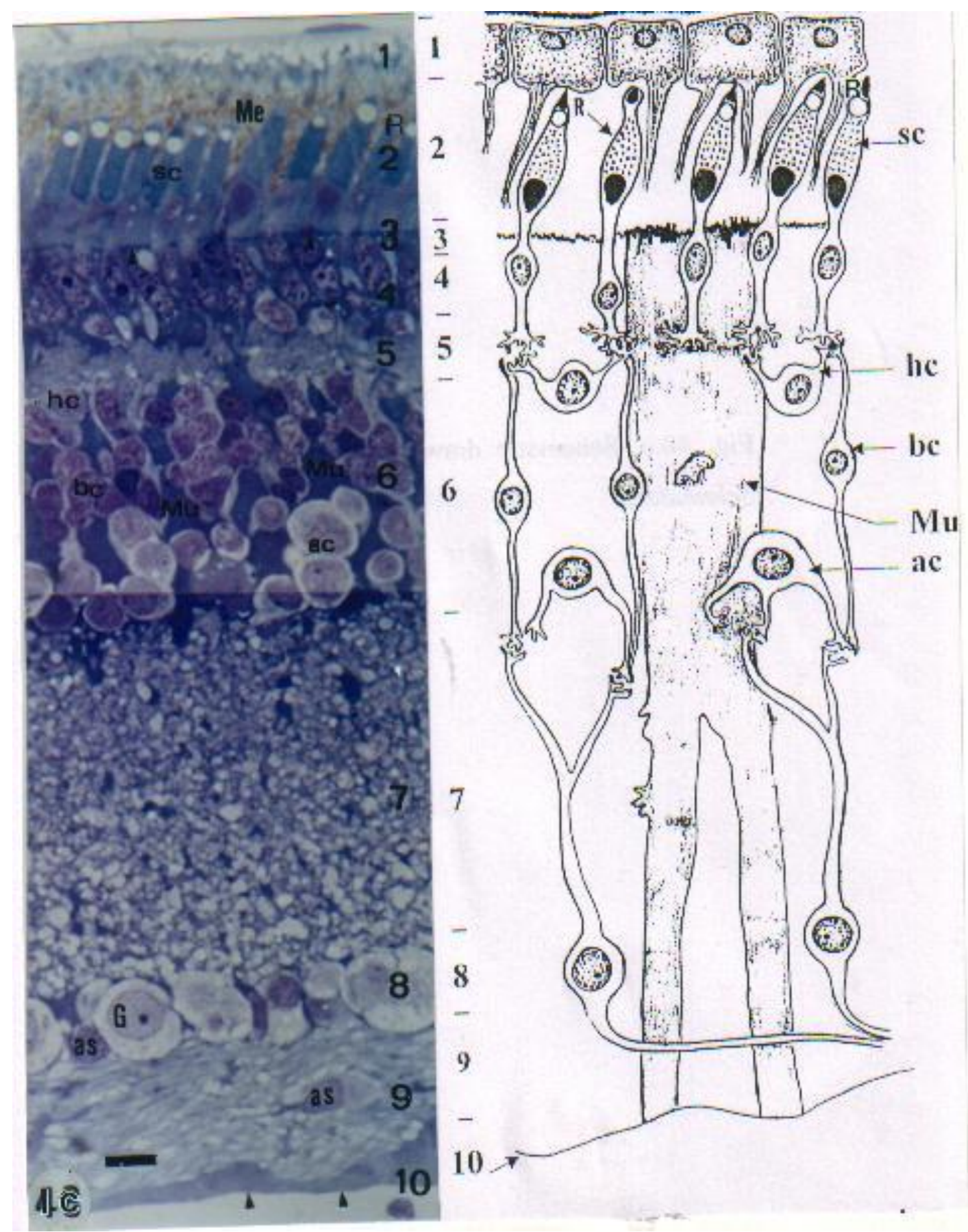


Fairoze Khattab et al

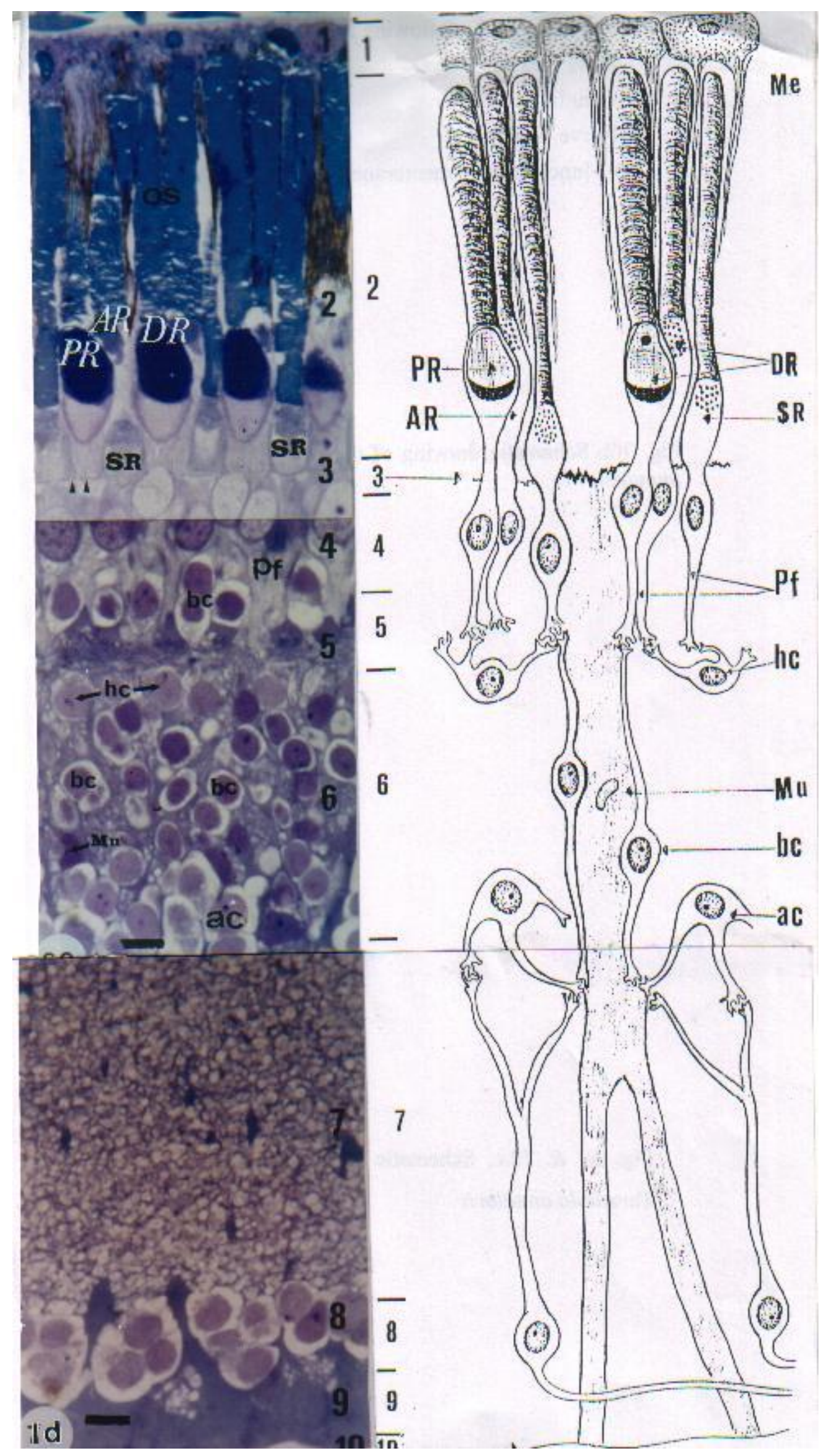


Ultrastructural Studies of The Pigment........
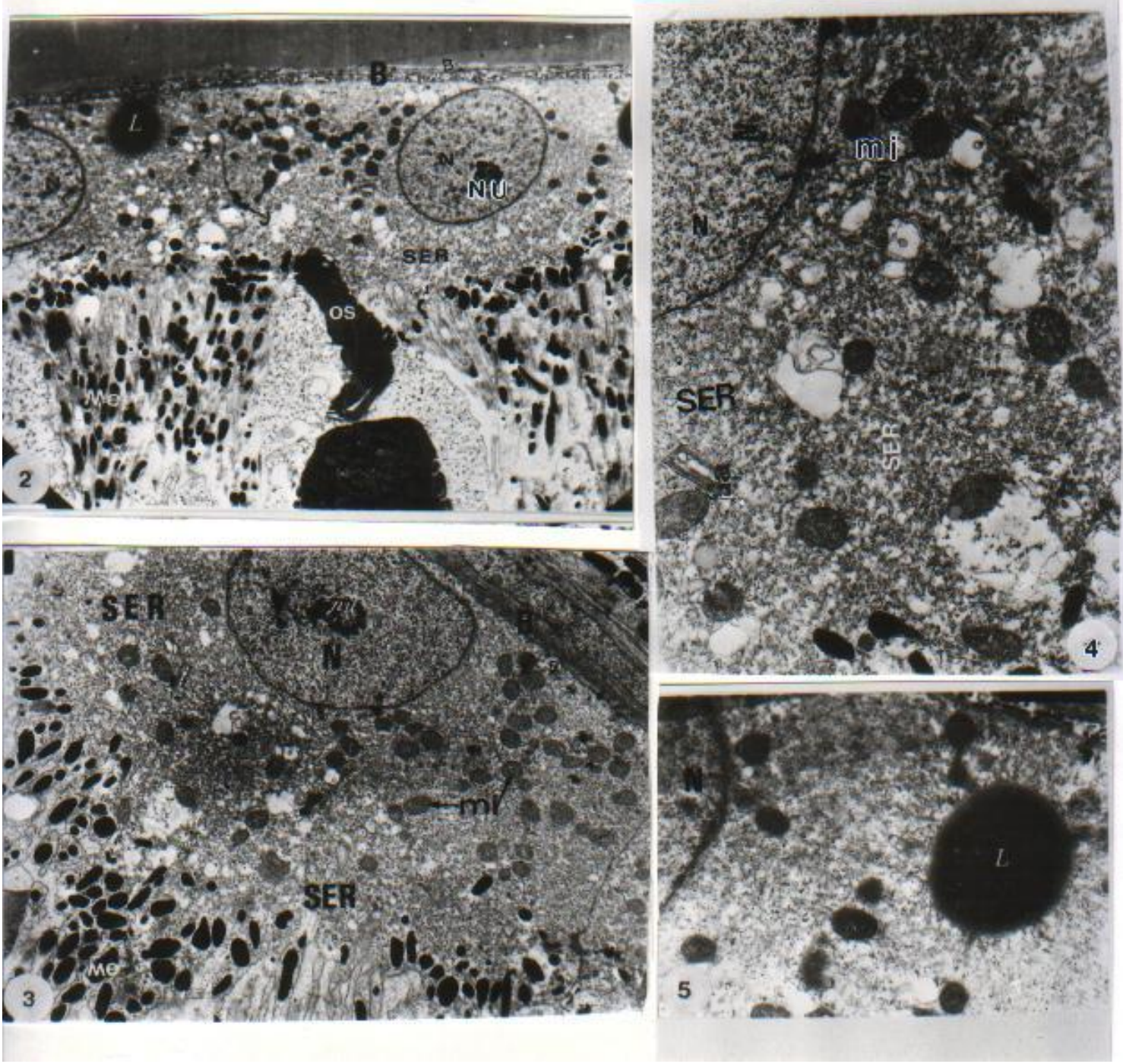
Fairoze Khattab et al

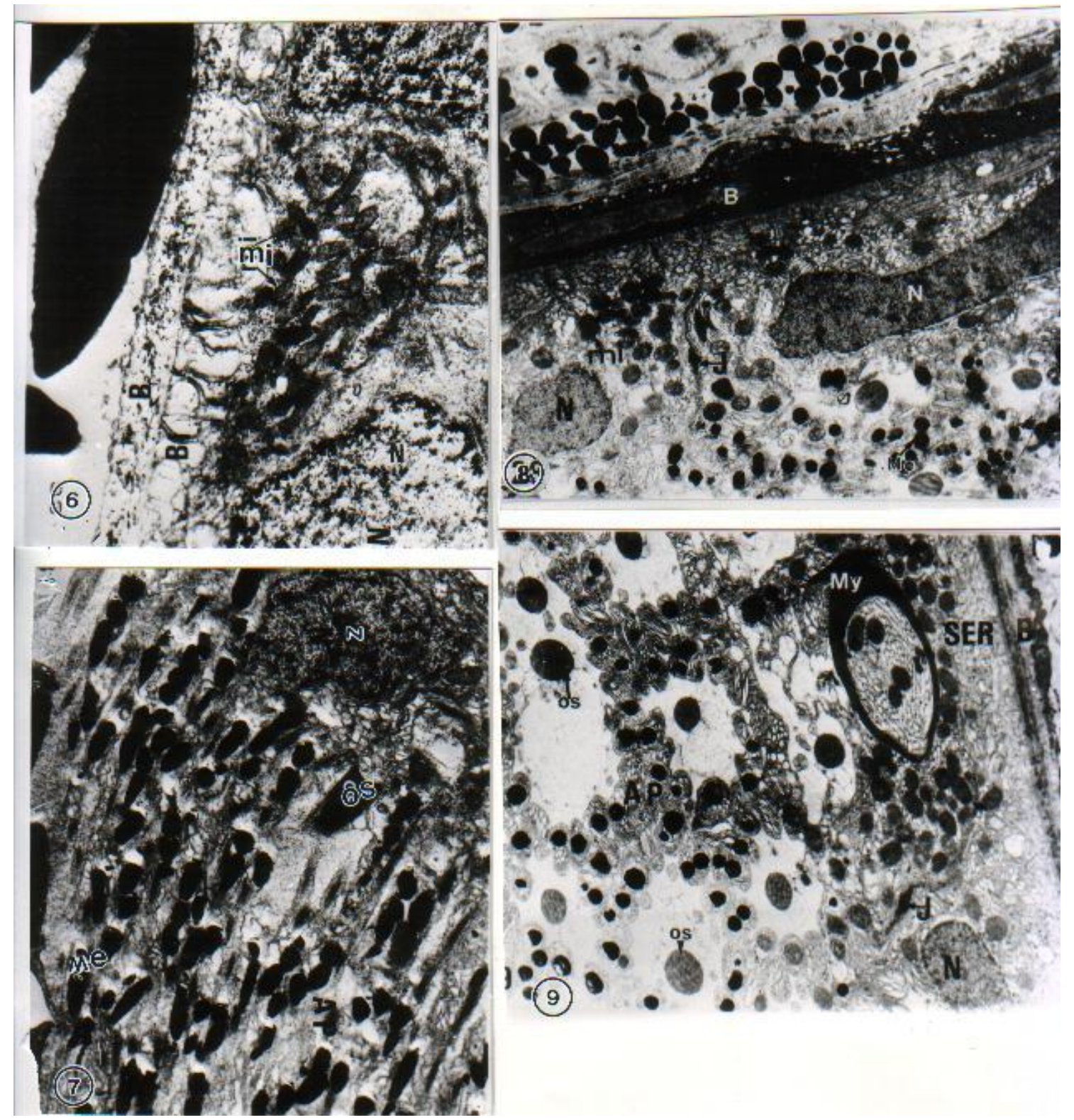



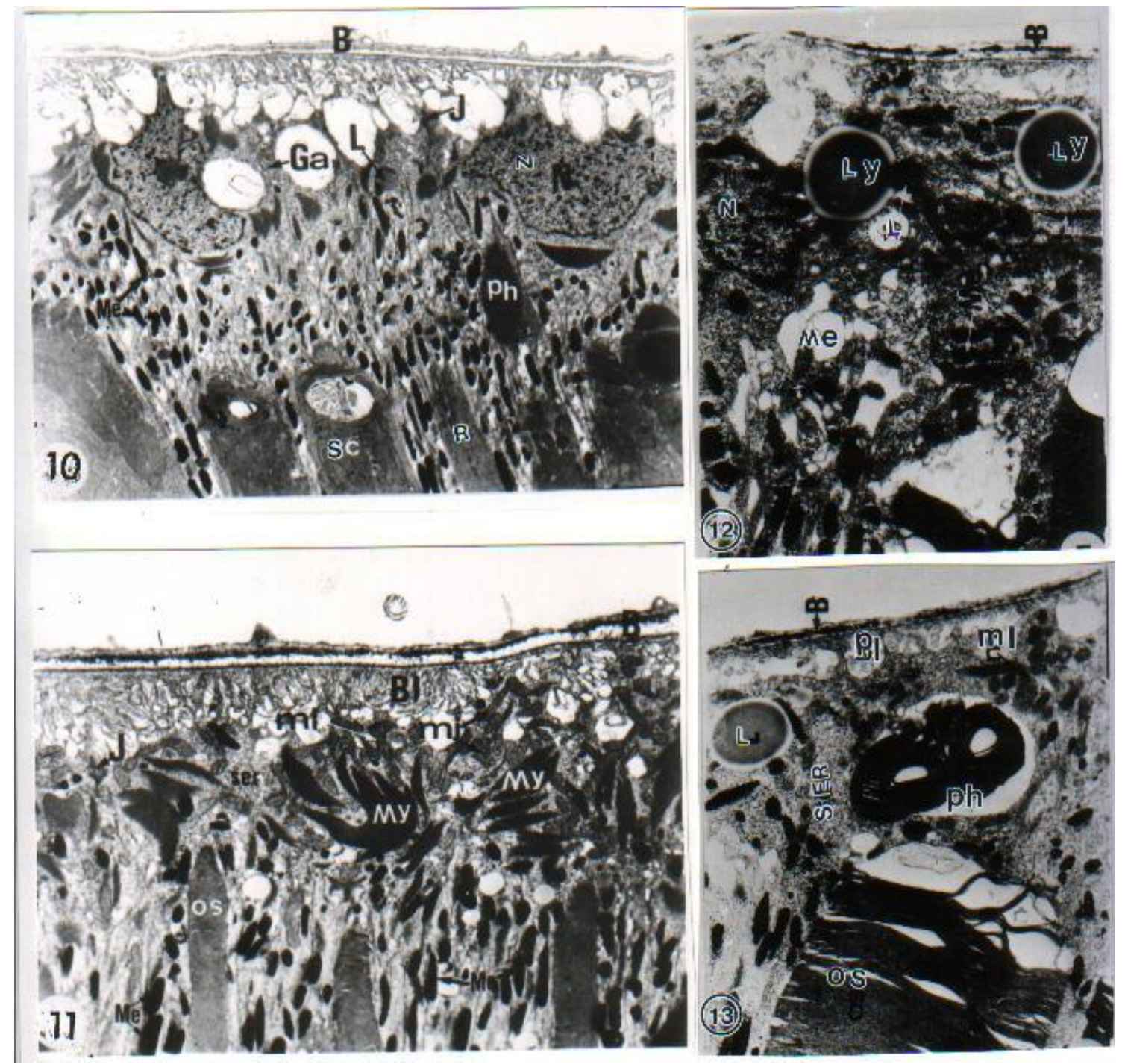


\section{Fairoze Khattab et al}

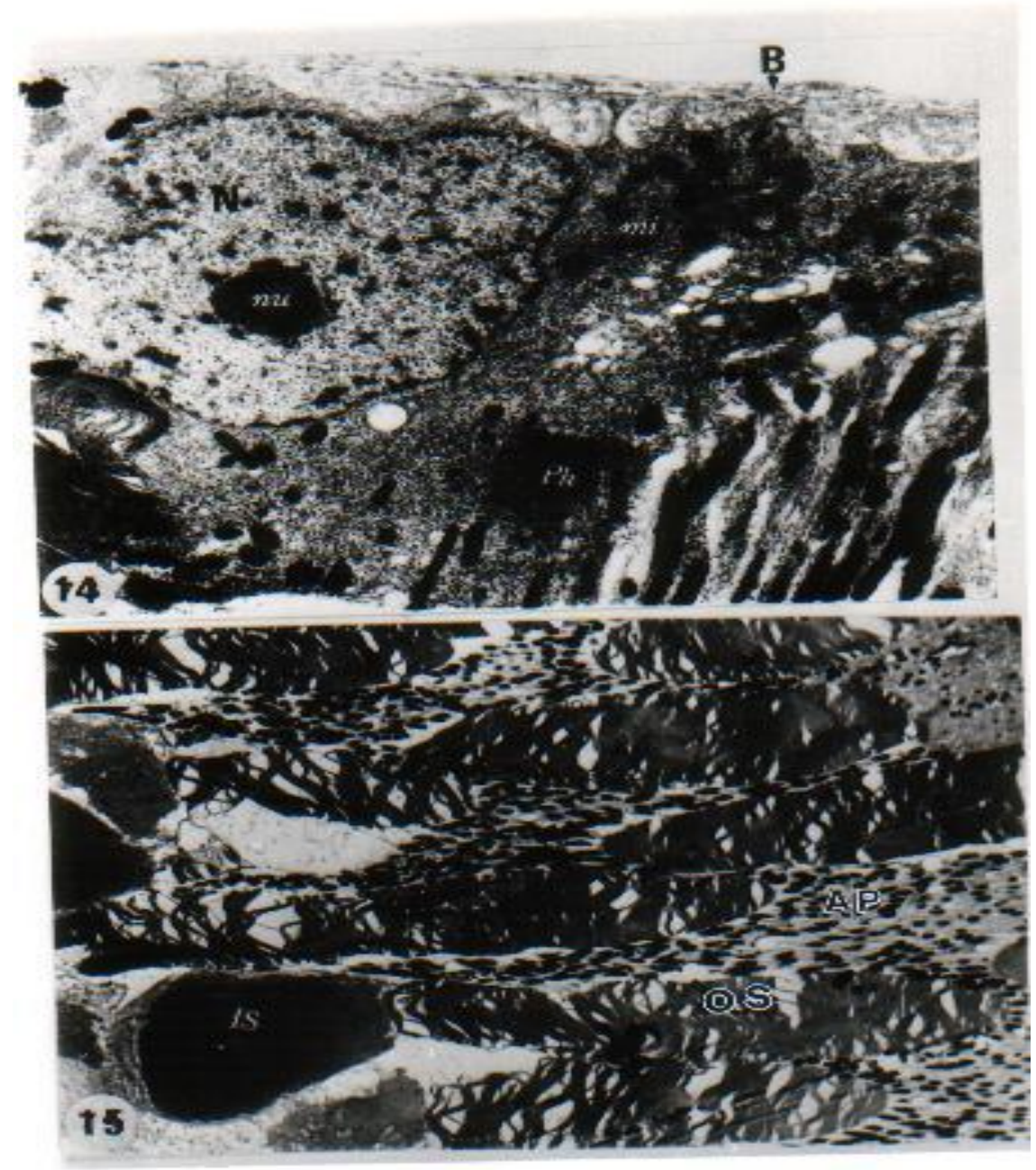

\section{Discussion}

The present work shows certain common features in the ultrastructure of the pigment epithelial cells of four different species of reptiles. Among these features was the abundance of smooth endoplasmic reticulum and accumulation of a large number of mitochondria. The preponderance of the smooth endoplasmic reticulum is very likely due to the heavy involvement of this epithelium in the production, storage, transport and estrification of the lipid precursors of the visual pigments (Zinn and Benjamin,1979 and Braekevelt and Richardson,1996).

Although lipid droplets were observed in the retinal pigment epithelium in the four different reptilian species, yet their number, size and distribution were different .In Tarentola annularis a lizard with a nocturnal habitat ,the pigment epithelium contains a large number of variable size lipid droplets. In Eumeces schneiderii and Chameleo chameleon are diurnal reptiles have infrequent fine lipid droplets .The pigment epithelium of Cerastes cerastes, which has both nocturnal and diurnal habitat, occupies a middle position in the fine structure of their lipid droplets, which are represented by one large droplet in each cell. Although the actual function of lipid droplets in different animal species is still uncertain (Breaekevelt and Richardson, 1996),some authors suggested that these droplets could be storage areas for vitamin A or related compounds (Young and Bok, 1970;Kuwabara, 1979).

Myoid bodies, which appear as stacks of smooth surfaced membranes were detected within the retinal pigment epithelial cells of both Chameleo chameleon and Eumeces schneiderii (diurnal lizards). They were not found in the other two species 
Tarentola annularis (nocturnal) and Cerastes cerastes (with both nocturnal and diurnal). The present observations accommodate with those of Braekevelt (1993; and 1994) who suggested that myoid bodies are not present within the retinal pigment epithelial cells of animal species that are not light adapted. The function of myoid bodies is uncertain although they have been implicated as the structures that trigger photomechanical movements (Porter and Yamada , 1960) as well as being storage sites for lipids prior to esterification (York and Dickson ,1984 \& 1985). The abundance of mitochondria within retinal pigment epithelial cells which is a common feature in all four reptilian species is an indicative of the high energy requirement of these cells as they fulfill their several important functions, (Braekevelt, 1994).

In contrast with the other three reptalian species, in Tarentola annularis, numerous phagosomes were found in the retinal pigment epithelium. This observation is in accordance with the report of Mcllwain (1996) who suggested that phagosomes are formed in the retinal pigment epithelium as a result of shedding of rod discs which occur at about daybreak in a circadian rhythm and continuous if the animal is kept in the dark.

\section{References}

1. Bowmaker, J. (1991): The Evolution of Vertebrate Visual Pigments and Photoreceptors. In: Evolution of the Eye and Visual System, ed. By John, R. and Richard, L. CRC Pree, Ann Arbor, Boston, Boca Reton.

2. Braekevelt, C. R. (1980): Fine structure of the retinal epithelium and tapetum lucidum in the gaint danio Danio malabricus (Teleost). Anat. Embryol., 158:317-328.

3. Braekevelt, C.R.(1986): Retinal epithelial fine structure in the grey seal Halichoerus grypus. Acta. Anat.,127:255-261.

4. Braekevelt, C.R.(1988):Retinal epithelial fine structure in the veret monkey (Cercopithecus aethiops). Histol. Histopathol.,3:3338.

5. Braekevelt, C.R.(1992):Retinal epithelial fine structure in the southern fiddler ray (Trygonorhina fasciata).Histopathol.,7:275282.

6. Braekevelt, C.R.(1993):Fine structure of the retinal epithelium of the tiger salam- ander (Ambystoma tigrinum). Histol. Histopatho 1.,ㅁ:257-264.

7. Braekvelt, C. R.(1994): Fine structure of the retinal pigment epithelium in the Port Jackson Shark (Heterodontus phillipi). Anat. Embroyl.,190:501-506.

8. Braekvelt, C. R. and Richardson, $\mathbf{K}$. (1996): Retinal photoreceptor fine structure in Australian Galah (Eolophus roseicapillus). Histo. Histopathol.,11:555-564.

9. Davis, D. (1971): Histopathologic Technic and practical Histochemistry. Mc GrawHill ,New York 3rd ed.,112.

10. Kuwabara, T. (1979): Species differences in the retinal pigment epithelium. In the retinal pigment epithelium ed. By Zinn, $\mathrm{K}$. and Marmor, M. Harvard University Press, Cambridge.

11. Mcllwain, J.T.(1996):Photoreceptors and photoreception In :An introduction to the biology of vision Brown University Cambridge University Press.

12. Moyer, F. (1969):Development ,Structure and function of the retinal pigment epithelium, in the retina ed. By Straatsma, B. University of California Press, Los Angeles.

13. Nguyen-Legros, J.(1978):Fine structure of the pigment epithelium in the vertebrate retina.Int. Res. Cytol., [suppl.7]:278-328.

14. Porter, K. and Yamada, E. (1960): Studies on the endoplasmic reticulum. Its from and differentiation in pigment epithelial cells of the frog retina. J. Biophs. Biochem. Cytol.,ㅁ: 181-205.

15. Villee, C.; Solomon, E.; Martin, C. and Martin, L. (1989):Biology. Saunders College Pulb. (2nd ed.).San Francisco, London and Tokyo.

16. York, M. and Dickson, D.(1984):Diurnal variations in myoid bodies of the newt retinal pigment epithelium. Cell Tissue Res.,235:177-186.

17. York, M. and Dickson, D. (1985):A cytochemical study of myoid bodies in the retinal pigment epithelium of the newt Notophthalmus viridescens. Cell Tissue Res., 240:641-648.

18. Young, R. and Bok ,D.(1970): Autoradiographic studies of the retinal pigment epithelium. Invest. Opthalmol.9:524-536.

19. Zinn, K. and Benjamin H. J.(1979): Anatomy of the human retinal pigment epithelium. In :The retinal pigment epithelium. Harvard University Press, Cambridge. 


\section{دراسات بالميكروسكوب الضوئي و الميكروسكوب الاليكتروني علي الطبقة

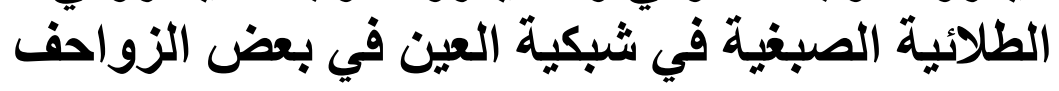 \\ فيروز خطاـ فهمي إبراهيم خطاب ـناجي فارس ـأمان زكي

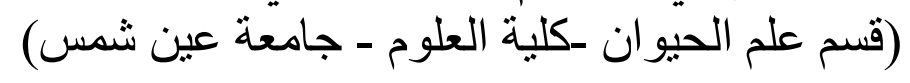

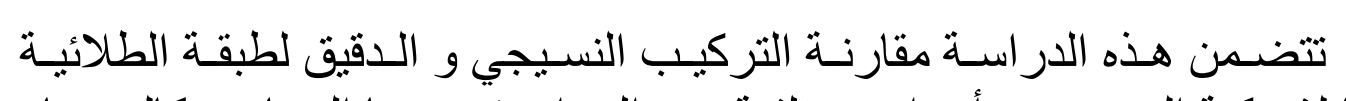

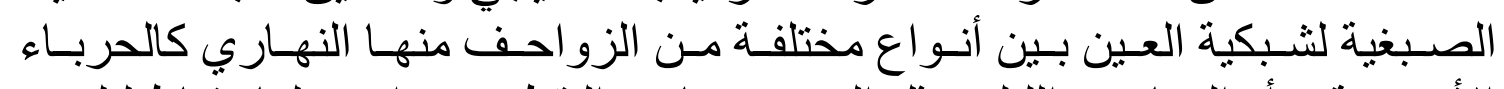

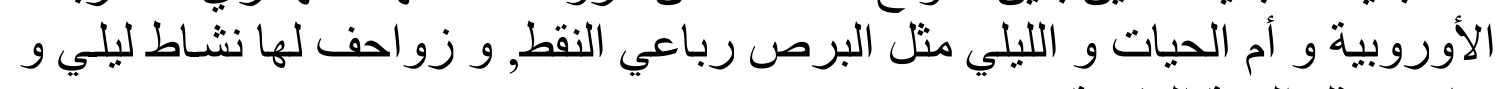
نهاري مثل الحية المقرنة.

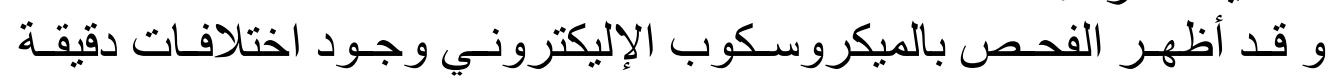

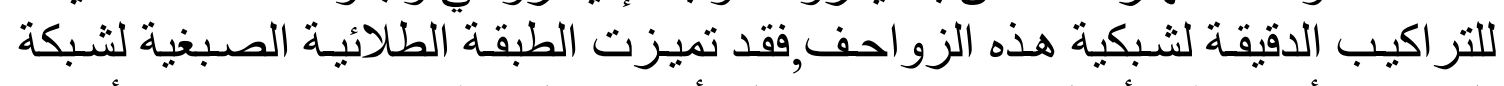

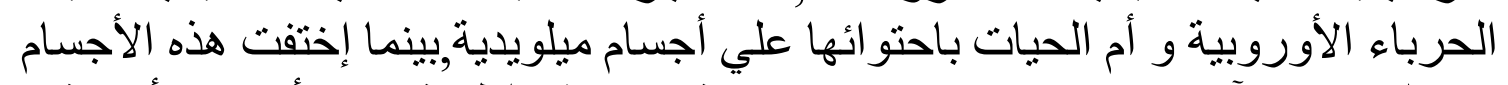

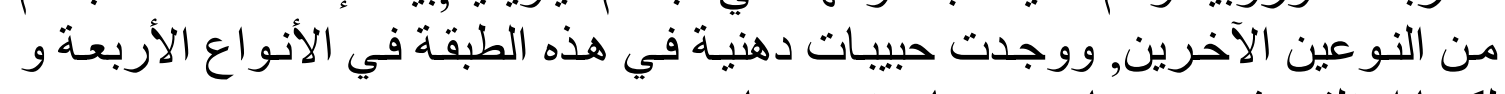

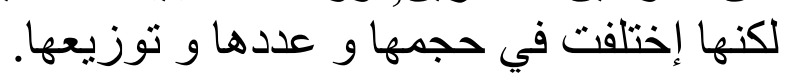

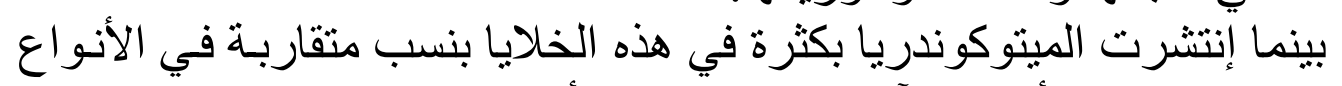

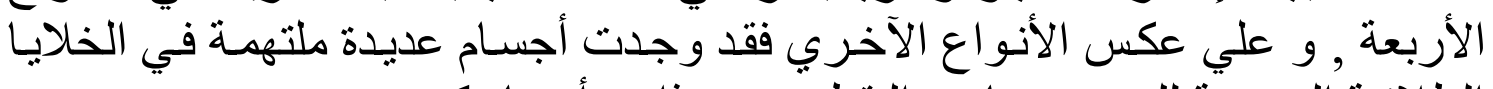

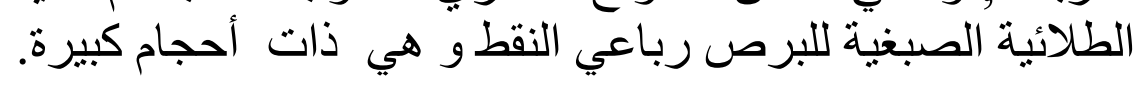

